\title{
Impact and outcome of cardiac diseases in pregnancy
}

\author{
Gira Dabhi*, Jignesh Chauhan, Munjal Pandya, Rahul Sinhar
}

Department of Obstetrics and Gynecology, AMC MET Medical College, Ahmedabad, Gujarat, India

Received: 22 November 2020

Revised: 06 December 2020

Accepted: 07 December 2020

\section{*Correspondence:}

Dr. Gira Dabhi,

E-mail: giradabhi@gmail.com

Copyright: (C) the author(s), publisher and licensee Medip Academy. This is an open-access article distributed under the terms of the Creative Commons Attribution Non-Commercial License, which permits unrestricted non-commercial use, distribution, and reproduction in any medium, provided the original work is properly cited.

\begin{abstract}
Background: Present study done to study incidence, effect of pregnancy on cardiac disease and vice-versa and fetomaternal outcome in patients with cardiac disease in pregnancy at tertiary care hospital.

Methods: It's a retrospective observational study conducted in Department of OBGY at tertiary care hospital between 01 June 2019 to 31 May 2020. 28 cases of cardiac disease out of 8659 patients registered included in the study. Demographic data like age, parity, etiological factors of cardiac disease, mode of delivery, neonatal outcome noted from case records.

Results: In study, $32 \%$ were unregistered cases and $10.7 \%$ had never sought any medical care before. Majority (53.6\%) cases belonged to $20-25$ years. Heart disease noted to be more in primipara (35.7\%). $71.4 \%$ belonged to NYHA class $1+2$ and had a relatively uneventful peripartum period. Majority $(53.6 \%)$ patients had rheumatic valvular disease. Cases of Congenital heart disease were $17.8 \%$, pulmonary artery hypertension was $25 \%$, Maternal mortality were $2(7.2 \%)$. 46.5\% women delivered with caesarean section. PIH (18\%) and anemia (7.2\%) were most commonly associated conditions. $85.6 \%$ women delivered live newborns and full term, pre-term deliveries and IUGR were $71.4 \%, 17.8 \%$ and $10.7 \%$ respectively.

Conclusions: Rheumatic origin is the most common cardiac disease associated with pregnancy. The availability of early diagnostic techniques and reference to tertiary care centre, timely admission and close monitoring of patient and delivery with multidisciplinary approach include specialized cardiologic care, high risk obstetric support and neonatology expertise can minimize feto-maternal morbidity and mortality. Pre-conceptional counselling, regular antenatal check-ups and contraceptive advice must be included in counselling part.
\end{abstract}

Keywords: Cardiac disease, Feto-maternal outcome, Maternal death

\section{INTRODUCTION}

A century ago, some authorities recommended that women with heart disease should be dissuaded from marriage, as pregnancy with heart disease was considered life threatening during that time due to lack of medical facilities. But, now in modern era, progress in early diagnostic procedures, advancement in medical and surgical treatment has resulted in larger number of women with heart disease surviving to child-bearing years and proceeding with pregnancy. Although, cardiac disease complicates more than $1 \%$ of all pregnancies and is now the leading cause of indirect maternal deaths accounting for $20 \%$ of all cases, maternal cardiac disease is a major cause of non-obstetric maternal morbidity and mortality. ${ }^{1}$ In developing countries like India, rheumatic heart disease still contributes to the highest cases among cardiac disease in pregnancy.

\section{Pathophysiology}

The marked pregnancy induced anatomical and functional changes in cardiac physiology have a profound effect on underlying heart disease. Plasma volume and 
cardiac output begins to increase in early pregnancy. Some of these changes are listed in table 1 given below. ${ }^{1}$

Table 1: Pregnancy related changes in cardiac and circulatory system.

\begin{tabular}{|ll|}
\hline Parameter & Changes in \% \\
\hline Cardiac output & +43 \\
\hline Heart rate & +17 \\
\hline $\begin{array}{l}\text { Left ventricular stroke volume } \\
\text { index }\end{array}$ & +17 \\
\hline Systemic vascular resistance & -21 \\
\hline Pulmonary vascular resistance & -34 \\
\hline Mean arterial pressure & +4 \\
\hline Colloidal osmotic pressure & -14 \\
\hline
\end{tabular}

Heart of a normal pregnant woman without any cardiac diseases can withstand above mentioned adaptation during pregnancy. But, women with cardiac disease can't always accommodate these changes, can lead to ventricular dysfunction and cardiogenic heart failure. Maximum cardiac output and plasma volume occurs around 32 weeks. Maximum amount of blood come back to body just after delivery. So, majority of pregnant woman with heart disease can have symptoms of heart failure at around 32 weeks or during peripartum period (during or immediately after delivery). ${ }^{1}$

\section{Clinical indicators of heart disease in pregnancy}

Pregnant woman with heart disease can have symptoms like progressive dyspnoea or orthopnoea, nocturnal cough, haemoptysis, syncope, chest pain etc. Clinical findings like cyanosis, clubbing of fingers, neck veins dilated, systolic murmur $\mathrm{Gr} \geq 3 / 6$, diastolic murmur, cardiomegaly, tachycardia or arrhythmia, split second heart sound, fourth heart sound, criteria for pulmonary hypertension etc. ${ }^{1}$

In this study, we sought to evaluate the incidence, to better understand the impact of pregnancy on cardiac disease and vice-versa, in order to guide efforts to improve maternal health. Furthermore, we sought to evaluate the maternal and neonatal outcome in women presented with cardiac disease.

\section{METHODS}

It is retrospective observational study carried out at tertiary care institute (L G Hospital, Ahmedabad) from 1st June 2019 to 31st May 2020.

\section{Inclusion criteria}

All the pregnant women, with singleton pregnancy, which were known cases or newly diagnosed as having cardiac diseases were included.

\section{Exclusion criteria}

Multifetus pregnancy were excluded.

Total 28 cases of cardiac disease out of 8659 patients registered included in the study. The cases under the study were, with a known cardiac diagnosis prior to or during pregnancy period, both booked and unbooked cases and also referred cases from urban centres, admitted for management. Demographic data like age, parity, etiological factors of cardiac disease, mode of delivery noted from case records. Proper history and thorough clinical examination was done to find out the type of cardiac lesion, any signs of heart failure and stage of pregnancy. Cases were graded as per NYHA classification of grade of heart disease. Diagnostic modalities like echocardiogram (ECG), echocardiography, chest and abdominal X-ray, cardiovascular MRI etc. used. ${ }^{1}$ Cases were referred to medical specialist for confirmation of cardiac disease and to seek their opinion regarding management. Patients were advised to have regular antenatal check-up. Cases were followed in post-partum period for up to 6 weeks and fetal outcome data was collected from case records and data from neonatal ICU.

All of this data has presented and analysed in numbers and percentage using Microsoft excel.

\section{Statistical analysis}

Statistical analysis was done by Microsoft Excel.

\section{RESULTS}

Present study includes 28 pregnant women with cardiac disease in OBGY department at our institute during 1st June 2019 to 31st May 2020. A total of 8659 women delivered during this time period.

Our study shows $0.32 \%$ incidence of cardiac disease in pregnant women which is comparable to the study made by Biswas et al (2016), which had the incidence of $0.24 \%$. $^{2}$

In this study, from total 28 cases, 10 were registered under hospital and 9 were unregistered (Table 2).

Table 2: Registered vs emergency cases.

\begin{tabular}{|lll|}
\hline Total no of cases & Registered & Unregistered \\
\hline $\mathbf{2 8}$ & $19(68 \%)$ & $9(32 \%)$ \\
\hline
\end{tabular}

Present study shows about $53.6 \%$ of the women having cardiac disease were in the age group of 20-25 years. $35.7 \%, 7.2 \%$ and $3.6 \%$ of the women were in age group of 26-35 years, >35 years and <20 years respectively (Table 3). 
Table 3: Demographic data.

\begin{tabular}{|c|c|c|c|c|}
\hline \multirow{2}{*}{$\begin{array}{l}\text { Maternal } \\
\text { age (in } \\
\text { years) }\end{array}$} & \multicolumn{2}{|c|}{$\begin{array}{l}\text { This study } \\
\text { total }=28 \text { cases }\end{array}$} & \multicolumn{2}{|c|}{$\begin{array}{l}\text { Tahira et al } 2012^{3} \\
\text { total=74 cases }\end{array}$} \\
\hline & No. & $\%$ & No. & $\%$ \\
\hline$<20$ & 1 & 3.6 & 6 & 8.1 \\
\hline $20-25$ & 15 & 53.6 & 31 & 41.9 \\
\hline $26-35$ & 10 & 35.7 & 32 & 43.2 \\
\hline$>35$ & 2 & 7.1 & 5 & 6.8 \\
\hline
\end{tabular}

Table 4: Parity and heart disease.

\begin{tabular}{|lllllll|} 
Parity & $\begin{array}{l}\text { This study } \\
\text { Total=28 } \\
\text { cases }\end{array}$ & $\begin{array}{l}\text { Joshi et al } \\
\mathbf{2 0 1 5}^{\mathbf{4}} \\
\text { Total=42 } \\
\text { cases }\end{array}$ & \multicolumn{2}{l}{$\begin{array}{l}\text { Sheila et al } \\
\text { 20095 } \\
\text { Total=95 } \\
\text { cases }\end{array}$} \\
& No. & \% & No. & \% & No. & \% \\
\hline G1 & 10 & 37.7 & 30 & 71.4 & 42 & 44.2 \\
\hline G2 & 8 & 28.6 & 7 & 16.7 & 25 & 26.4 \\
\hline G3 & 7 & 25 & 3 & 7.1 & 16 & 16.8 \\
\hline >G3 & 3 & 10.7 & 2 & 4.8 & 12 & 12.6 \\
\hline
\end{tabular}

The present study shows $64.3 \%$ of women having low parity (G1-2) and $35.7 \%$ of patients were having parity $\geq \mathrm{G} 3$ (Table 4).
At first antenatal visit, our study shows $71.4 \%$ of the cases belonging to NYHA class I+II. $21.4 \%$ and $7.2 \%$ of cases were belonging to NYHA class III and class IV respectively (Table 5).

Table 5: NYHA grade of heart disease and pregnancy.

\begin{tabular}{|lllll|}
\hline $\begin{array}{l}\text { NYHA } \\
\text { class }\end{array}$ & \multicolumn{2}{l}{$\begin{array}{l}\text { This Study } \\
\text { total=28 Cases }\end{array}$} & \multicolumn{2}{l|}{$\begin{array}{l}\text { Gehlot H el al } \mathbf{2 0 1 8}^{\mathbf{6}} \\
\text { total=25 Cases }\end{array}$} \\
\cline { 2 - 5 } No. & \% & No. & \% \\
\hline Class I & 11 & 39.3 & 11 & 44 \\
\hline Class II & 9 & 32.1 & 6 & 24 \\
\hline Class III & 6 & 21.4 & 8 & 32 \\
\hline Class IV & 2 & 7.2 & - & - \\
\hline
\end{tabular}

In present study, $53.6 \%$ of cases were having rheumatic valvular heart disease, whereas, other causes like congenital heart disease, peripartum cardiomyopathy, congestive heart failure, pulmonary artery hypertension, prosthetic valve replacement were seen in $17.8 \%, 14.3 \%$, $10.7 \%, 25 \%$ and $3.6 \%$ respectively (Table 6 ).

Pulmonary oedema $25 \%$, peripartum cardiomyopathy $10.7 \%$ and congestive heart failure $10.7 \%$ were common complications seen in present study. Non-cardiac complications like $\mathrm{PIH}$, wound gap, APH and anaemia were seen in $18 \%, 3.6 \%, 3.6 \%$ and $7.2 \%$ of patients respectively. Maternal mortality was $7.2 \%$ (Table 7).

Table 6: Clinical spectrum of cardiac disease.

\begin{tabular}{|c|c|c|c|c|c|c|}
\hline \multirow{2}{*}{ Etiology } & \multicolumn{2}{|c|}{$\begin{array}{l}\text { This study } \\
\text { Total=28 cases }\end{array}$} & \multicolumn{2}{|c|}{$\begin{array}{l}\text { Gehlot el al } 2018^{6} \\
\text { Total=25 cases }\end{array}$} & \multicolumn{2}{|c|}{$\begin{array}{l}\text { Joshi el al } 2015^{4} \\
\text { Total }=42 \text { cases }\end{array}$} \\
\hline & No. & $\%$ & No. & $\%$ & No. & $\%$ \\
\hline Rheumatic valvular heart disease & 15 & 53.6 & 14 & 56 & 30 & 71.4 \\
\hline Congenital heart disease & 5 & 17.8 & 2 & 8 & 6 & 14.3 \\
\hline Peripartum cardiomyopathy & 4 & 14.3 & 2 & 8 & 3 & 7.1 \\
\hline Congestive heart failure & 3 & 10.7 & - & - & - & - \\
\hline Pulmonary arterial hypertension & 7 & 25 & 4 & 16 & - & - \\
\hline Prosthetic valve replacement & 1 & 3.6 & 3 & 12 & 3 & 7.1 \\
\hline
\end{tabular}

Table 7: Complications associated with cardiac disease in pregnancy.

\begin{tabular}{|c|c|c|c|c|c|c|}
\hline \multirow[t]{2}{*}{ Complication } & \multicolumn{2}{|c|}{$\begin{array}{l}\text { This study } \\
\text { Total }=28 \text { cases }\end{array}$} & \multicolumn{2}{|c|}{$\begin{array}{l}\text { Sapna Shah et al } 2013^{7} \\
\text { Total=34 cases }\end{array}$} & \multicolumn{2}{|c|}{$\begin{array}{l}\text { Joshi et al } 2015^{4} \\
\text { Total }=42 \text { cases }\end{array}$} \\
\hline & No. & $\%$ & No. & $\%$ & No. & $\%$ \\
\hline Thromboembolism & - & - & 1 & 2.9 & - & - \\
\hline Rhythm disorder (AF) & 2 & 7.2 & 2 & 5.9 & - & - \\
\hline Pulmonary edema & 7 & 25 & 8 & 23.5 & - & - \\
\hline Congestive heart failure & 3 & 10.7 & 5 & 14.7 & 7 & 16.7 \\
\hline Syncopal attack & 1 & 3.6 & 1 & 2.9 & - & - \\
\hline Peripartum cardiomyopathy & 3 & 10.7 & 3 & 8.8 & 2 & 4.8 \\
\hline Maternal death & 2 & 7.2 & 1 & 2.9 & 2 & 4.8 \\
\hline \multicolumn{7}{|l|}{ Non-cardiac Complications } \\
\hline $\mathrm{PIH}$ & 5 & 18 & - & - & 5 & 11.9 \\
\hline Wound gap & 1 & 3.6 & - & - & - & - \\
\hline APH & 1 & $3.6 \%$ & - & - & 2 & 4.8 \\
\hline Anaemia & 2 & $7.2 \%$ & - & - & 3 & 7.1 \\
\hline PPH & - & - & - & - & 5 & 11.9 \\
\hline
\end{tabular}


Table 8: Mode of delivery.

\begin{tabular}{|c|c|c|c|c|c|c|}
\hline \multirow[t]{2}{*}{ Mode of delivery } & \multicolumn{2}{|c|}{$\begin{array}{l}\text { This study } \\
\text { Total=28 cases }\end{array}$} & \multicolumn{2}{|c|}{$\begin{array}{l}\text { Soma Pillay et al } 2008^{8} \\
\text { Total=188 cases }\end{array}$} & \multicolumn{2}{|c|}{$\begin{array}{l}\text { Sima Biswas et al } 2016^{2} \\
\text { Total }=50 \text { cases }\end{array}$} \\
\hline & No. & $\%$ & No. & $\%$ & No. & $\%$ \\
\hline Caesarean Section & 13 & 46.5 & 75 & 39.9 & 16 & 32 \\
\hline Preterm CS & 3 & 10.7 & 15 & 6.9 & 5 & 10 \\
\hline Term CS & 10 & 35.7 & 60 & 32.9 & 11 & 22 \\
\hline Vaginal Delivery & 12 & 42.8 & 82 & 43.6 & 24 & 48 \\
\hline Preterm ND & 2 & 7.1 & 16 & 7.4 & 8 & 16 \\
\hline Term ND & 10 & 35.7 & 66 & 36.2 & 16 & 32 \\
\hline Abortion & 3 & 10.7 & 25 & 11.7 & - & - \\
\hline
\end{tabular}

Table 9: Fetal outcome.

\begin{tabular}{|c|c|c|c|c|}
\hline & \multicolumn{2}{|c|}{ This study total $=25$ cases } & \multicolumn{2}{|c|}{ Patil et al $2014^{9}$ total $=60$ cases } \\
\hline & No. & $\%$ & No. & $\%$ \\
\hline Preterm & 5 & 17.8 & 12 & 20 \\
\hline IUFD & 1 & 3.7 & 7 & 11.7 \\
\hline NICU Admissions & 7 & 25 & 6 & 10 \\
\hline IUGR & 3 & 10.7 & 19 & 31.7 \\
\hline
\end{tabular}

Out of 28 cases, 3 cases had abortion and 25 cases delivered after the age of viability. In this study, (13) $46.4 \%$ of the cases were delivered by caesarean section and (12) $42.8 \%$ delivered vaginally. $17.8 \%$ of preterm deliveries occurred in this study (Table 8).

In this study, 25(89.3\%) patients delivered after age of viability with $20(71.4 \%)$ term deliveries and $5(17.8 \%)$ preterm deliveries. The incidence of IUGR, NICU admission and IUD is $3(10.7 \%), 7(25 \%)$ and $1(3.7 \%)$ respectively. Out of the 7 NICU admissions, 6 babies recovered successfully and were discharged, 1 baby expired due to preterm with RDS (Table 9).

\section{DISCUSSION}

As shown in Table 1, in this study, out of total 28 cases, 19 were registered under hospital and 9 were unregistered. Maternal morbidity and mortality increase in unregistered cases who have not taken any treatment.

As shown in Table 2, in this study, about $53.6 \%$ of the women having cardiac disease were in the age group of $20-25$ years. $35.7 \%, 7.2 \%$ and $3.6 \%$ of the women were in age group of 26-35 years $>35$ years and $<20$ years respectively. It corresponds to Tahira et al study which shows $41.9 \%$ and $43.2 \%$ of the cases in $20-25$ years and 26-35 years of age group respectively. ${ }^{3}$ Proper preconceptional counselling especially in early teenage years which includes proper knowledge regarding effects of pregnancy on heart condition, neonatal/perinatal risks and ways to optimize their cardiac conditions before pregnancy occurs.

As shown in Table 3, in this study, $64.3 \%$ of women having low parity (G1-2) and $35.7 \%$ of patients were having parity $\geq \mathrm{G} 3$ which corresponds with the study of Joshi et al which is respectively $88 \%$ and $12 \%$ and Sheila et al which is respectively $70.6 \%$ and $29.4 \% .^{4,5}$ The incidence of cardiac diseases is more common in women with low parity (G1-2). As this condition is associated with high maternal morbidity and mortality, further pregnancy is discouraged.

As shown in Table 4, in this study, $71.4 \%$ of the cases belonging to NYHA class I+II. This was comparable to study by Gehlot et al shows $68 \%$ cases with NYHA I+II and $32 \%$ cases with NYHA III. ${ }^{6}$ Most of the patients with class I or II delivered uneventfully. Patients of Class III or IV were admitted immediately and required close monitoring for good maternal and perinatal outcome. It is important to classify the disease at each antenatal visit. NYHA class I or II patients may worsen during the course of pregnancy.

As shown in Table 5, in this study, 53.6\% of cases were having rheumatic valvular heart disease, which is comparable to Study by Gahlot et al showed $56 \%$ and Joshi et al showed $71.4 \%$ incidence of RHD. In developing countries like India, incidence of rheumatic heart disease is still high as compared to developed countries where incidence of congenital disease is higher than RHD. ${ }^{4,6}$

As shown in Table 6, pulmonary oedema 25\%, peripartum cardiomyopathy $10.7 \%$ and congestive heart failure $10.7 \%$ were common complications seen in present study which corresponds to the study by Shah et al which had similar rates of $23.5 \%$ and $8.8 \%$ and $14.7 \%$ respectively. $^{7}$ Non-cardiac complications like $\mathrm{PIH}$, wound gap, APH and anaemia were seen in 18\%, 3.6\%, $3.6 \%$ and $7.2 \%$ of patients respectively in present study which is comparable to study by Joshi et al. ${ }^{4}$ Maternal mortality was $7.2 \%$. In our study, causes of death in both patients were congestive cardiac failure with peripartum cardiomyopathy, both the mortality occurred in postpartum period. Non-cardiac conditions like PIH, 
anemia, diabetes etc can complicate and worsens cardiac disease in pregnancy.

As shown in Table 7 , in this study, out of 28 cases, 3 cases had abortion and 25 cases delivered after the age of viability. Out of this, (13) $46.4 \%$ and (12) $42.8 \%$ had cesarean section and vaginal delivery respectively, which is comparable to study by Pillay et al study had CS rate of $39.9 \%$ and vaginal delivery rate of $43.6 \%$. CS was opted mainly in the case of obstetric indications. ${ }^{8}$ In 3 women, CS was opted because of cardiac indications which were severe pulmonary arterial hypertension $10.7 \%$. Assisted vaginal delivery by forceps/vacuum can be helpful to cut short the 2nd stage of labour and to reduce maternal exhaustion. In our study, $17.8 \%$ of deliveries occurred preterm which corresponds to study by Pillay et al Biswas et al which shows preterm in $14.3 \%$ and $26 \%$ respectively. This shows there is increased incidence of preterm deliveries in patients with cardiac diseases in pregnancy. ${ }^{2,8}$

As shown in Table 8, in this study, $25(89.3 \%)$ patients delivered after age of viability with $20(71.4 \%)$ term deliveries and $5(17.8 \%)$ preterm deliveries. Vaibhav Patil et al had $12(20 \%)$ preterm births as compared to our study. ${ }^{9}$ The incidence of IUGR, NICU admission and IUD is $3(10.7 \%), 7(25 \%)$ and $1(3.7 \%)$ respectively and study by Patil et al have $31.7 \%, 10 \%$ and $11.7 \%$ respectively. ${ }^{9}$ Out of the 7 NICU admissions, 1 baby expired due to preterm with RDS. This shows there is increased incidence of preterm and IUGR babies associated with cardiac disease in pregnancy.

\section{Limitations}

This study contains only small numbers of patients, was done in a particular medical college in particular area, it contains only lower- and middle-class belonging patients.

\section{CONCLUSION}

The outcome of this study reiterates the fact that maternal cardiac disease is still an important challenge for obstetricians. Valvular heart disease of rheumatic origin is the most common cardiac disease associated with pregnancy in the developing countries like India. The availability of adequate systems of early diagnosis of cardiac lesion, reference to tertiary care centre, timely admission and close monitoring of patient and delivery with multidisciplinary approach include specialized cardiologic care, high risk obstetric support and neonatology expertise that can minimize the serious consequences of poorly controlled heart disease in pregnancy and helps to improve Feto-maternal outcome. Women with cardiac conditions should be offered preconceptional counselling regarding effect of pregnancy on cardiac condition, effect of cardiac condition on pregnancy, the neonatal/perinatal risks and ways to optimize their cardiac condition before pregnancy occurs. Surgical correction of certain conditions before attempting pregnancy improves maternal as well as fetal outcome. The importance of regular antenatal check-up and contraceptive advice like barrier contraceptive, Progesterone only pills, IUCD, mirena etc. explained to avoid unwanted pregnancy and is essential part of counselling.

\section{ACKNOWLEDGMENTS}

I also thank to my PG teacher Dr. Dipti Shah madam, Dean and Professor in Department of Obstetrics and Gynaecology, AMC MET Medical College, Ahmedabad and Dr. Prakash Prajapati Sir, Asso Prof in Dept of Obstetrics and Gynaecology, AMC MET Medical College, Ahmedabad.

Funding: No funding sources

Conflict of interest: None declared

Ethical approval: Not required

\section{REFERENCES}

1. Cardiovascular Diseases. In: Cunningham FG, Lenovo KJ, Bloom SL, Hauth JC, Rouse DJ, Spong CY et al. Williams obstetrics. 24th Ed, New York, NY: McGraw-Hill. 2014;973-7.

2. Biswas S, Mandal I, Mandal AK. Heart disease in pregnancy and its feto-maternal outcome. J Dent Medic Sci. 2016;15:92-6.

3. Tahira T, Tahira S. Pregnancy; outcome in cardiac disease. Professional Med J Apr. 2012;19(2):145-9.

4. Joshi G, Joshi SC, Jha SK, Singh Y, Joshi A. Maternal heart disease and pregnancy outcome: Findings from a retrospective cohort in a tertiary care government hospital in Haldwani, Nainital. Nig J Cardiol 2015;12:120-3.

5. Sheela CN, Karanth S, Patil CB. Maternal cardiac complications in women with cardiac disease in pregnancy. Int J Pharm Biomed Res. 2011;2(4):2615.

6. Gehlot H, Singh N. Study of outcome of pregnancy in women with heart disease. Int $\mathbf{J}$ Reprod Contracept Obstet Gynecol. 2018;7(3):917-20.

7. Shah SR. Maternal cardiac disease and pregnancy outcome. Gujarat Medic J. 2013;68(1).

8. Pillay S, Macdonald AP, Mathivha TM, Bakker JL \& Mackintosh MO. Cardiac disease in Pregnancy: A 4year audit at Pretoria Academic Hospital. Sout Afric Med J. 2008;98(7):553-6.

9. Patil V, Bhingare P, Murthy B. Evaluation of Maternal and fetal outcome of pregnancy with heart disease with special reference to surgically corrected heart disease. Int J Sci Res Pub. 2014;4(9):1-5.

Cite this article as: Dabhi G, Chauhan J, Pandya M, Sinhar R. Impact and outcome of cardiac diseases in pregnancy. Int J Reprod Contracept Obstet Gynecol 2021;10:102-6. 